\title{
The good, the bad, and the blameless: A thematic analysis of the parental role in childhood obesity on an Internet discussion board
}

Terhi Koivumäki ( $\square$ terhi.koivumaki@tuni.fi )

Tampere University

Piia Jallinoja

Tampere University

\section{Research Article}

Keywords: Childhood obesity, parents, social media, obesity stigma, thematic analysis

Posted Date: December 13th, 2022

DOI: https://doi.org/10.21203/rs.3.rs-1187871/v2

License: (c) (1) This work is licensed under a Creative Commons Attribution 4.0 International License.

Read Full License 


\section{Abstract \\ Background}

Childhood obesity affects an increased percentage of families globally. For families, obesity is often a tense issue, not least because of the negative stigma and cultural perceptions associated with it.

Discussions around childhood obesity do not take place only at homes or in health care, but increasingly on social media, such as Internet discussion forums. On these platforms, parents, including those having a child with obesity, are exposed to cultural ways of framing childhood obesity, and defining who is responsible for children's weight.

\section{Method}

We gathered and analysed 16 discussion threads on childhood obesity taken from a Finnish internet discussion forum, vauva.fi, between 2015 and 2021 (a total of 331 posts). For the analysis, we chose threads where parents having a child with obesity took part. The data were analysed and interpreted with inductive thematic analysis.

\section{Results}

In the online discussion on childhood obesity, the posts were mostly about the reasons and solutions for obesity, and obesity was discussed in the context of parental responsibility and lifestyle choices within the family. We located three themes that were used to define parenthood: being a good parent, being a bad parent, and being a blameless parent. Parents listed healthy elements in their family's lifestyle to prove their good parenthood, whereas other commenters frequently tried to point out mistakes in the parents' behaviour or offer advice. Moreover, many acknowledged that some factors causing childhood obesity were outside the parents' influence. In addition, many parents brought up that they were genuinely ignorant of the reasons for their child's overweight.

\section{Conclusions}

Our results showed that for the parents and other commentators childhood obesity is not only a question of weight and lifestyle changes. Instead, defining good of parenting and related tasks was a recurring theme in the discussions. Consequently, counselling for parents in health care should be expanded from supporting a healthy lifestyle to strengthening parents' identity as being good enough parents. Furthermore, efforts should be made to increase parents' self-efficacy. In addition, supporting parents to accept and process feelings related to the child's weight would help them to adapt to their situation.

\section{Background}


Childhood obesity is a major concern in Finland and worldwide. In 2019, globally 38 million children under the age of 5 were overweight or obese, and the prevalence of childhood overweight among children and adolescents aged 5-19 has increased from 4\% (1975) to 18\% (2016) [1]. In 2020, in Finland, $29 \%$ of boys and $18 \%$ of girls aged $2-16$ years were overweight or obese [2]. There is a large and fairly consistent body of evidence demonstrating that obesity in childhood has adverse consequences on premature mortality and physical morbidity in adulthood [3].

A central cause for the increase is the changes in eating and physical activity behaviours that have changed the energy balance [4]. Our environment promotes excessive food intake and does not encourage physical activity [5]. There have been many simultaneous changes in the food environment, time use and built environment, leading to increased food supply and screen time, and decreased physical activity, that have increased children's energy intake and decreased their expenditure [6]. Due to these social, technological and environmental changes [7], it has become harder for parents to create a healthy environment for their children.

Given the above-described environmental influences, and the multifactorial nature of childhood obesity lifestyle change is not a straightforward issue. Previous studies among parents of children with obesity[1] have shown that often the case not to follow a healthier lifestyle is practical, such as a lack of time, resources, or concern with how to maintain good lifestyle choices in the family's own everyday life and surroundings [8-11]. Moreover, parents do not always recognise if their child is obese [8, 12-14]. Some parents feel that they already know enough about healthy lifestyles [8], and they might feel that health and happiness are more important than weight [15]. Alternatively, they might acknowledge that their child is overweight, but do not perceive it as a health risk [16]. When treating childhood obesity, targeting parents is an effective way to proceed [9], but to support parents better, we need more understanding on parents' conceptions on child's weight.

Moreover, a balance between managing child's obesity and considering the related psychosocial consequences needs to be found. Some parents fear that treating their child's obesity may harm the child $[8,12,17]$ or that parents are being blamed for the situation $[17,18]$. Indeed, obesity is typically attached to many negative attributes and cultural conceptions, that have an impact on parents. More specifically, several researchers have highlighted the stigma, i.e. negative social attitudes, related to overweight and obesity [19-21]. Stigmatisation includes stereotypes where people with obesity are seen as lazy, unmotivated, or lacking willpower [22]. The stigmatisation of children and adults with obesity can lead to a range of adverse outcomes such as impaired psychological wellbeing, social isolation, negative academic consequences, economic inequalities, and unhealthy eating and exercise behaviours [23].

In addition, parents of children with obesity may face stigmatisation. When seeking help for their child, parents are faced with a double moral burden: they feel they are blamed and shamed for the child's weight, but at the same time they fear the negative psychological effects of targeting the child's weight [24]. Parents of children with obesity may fear of being judged by health care professionals when they receive counselling about childhood obesity [18]. Parents easily feel isolated and blamed for causing their 
children's obesity and appreciate a supportive forum where they can share experiences [25]. Fear of stigmatisation or being seen as a bad parent can affect parents' readiness to seek help or discuss the weight of their child in health care [24]. For the parents feeling stigmatised, anonymous discussions on online platforms, may be an alternative to discussion in health care encounters [26]. This study aims to explore one such platform and how childhood obesity is discussed there by parents and other commentators.

Childhood obesity in social media

In contemporary societies, the Internet is a central platform where citizens search for information, inspiration, and advice on overweight, obesity, and weight management. More broadly, the Internet has increased citizen engagement with health-related issues, and various platforms have enabled citizens to search for information and support for their health-related concerns [27]. Easy access to the Internet and its various discussion forums in Western countries, such as Finland, have made these platforms also part of many parents' everyday lives [28]. The majority of parents use different parenting websites and social media to gain information on parenting, and higher-risk parents are even more likely to accept web-based information sources [29]. Furthermore as a US study suggested, people with stigmatized illnesses are more likely to use the Internet to get health information [30]. However, not all information on the Internet is accurate or promotes the wellbeing of citizens.

There is little previous research on parents' activity and argumentation in Internet forums in the context of childhood obesity. In a study based on two Australian online parenting discussion forums, four major themes were found related to the parents' use of forums: seeking advice, sharing advice, social support, and making judgements [31]. On these Australian forums, parents perceived childhood obesity as a public health concern, however, many brought up having difficulties in implementing the lifestyle change messages in everyday life [10]. In 2004, in an anonymous Finnish Internet discussion, parents were mainly viewed as the primary cause of childhood obesity. Parents were negatively described as having "lousy" characters and being unable to create an "adequate" emotional bond with their child, or as otherwise engaging in "faulty" child-rearing practices [32]. The negative sentiment dominating in the media can decrease the influence of health messages given to individuals [33].

We need more understanding about parents' perceptions of childhood obesity. Many parents seek help from social media forums, and consequently, it is vital to understand parents' online activity and arguments. Moreover, it is also essential to explore what kind of comments and answers these parents get and the tone of the overall discussion, because of the potential impact on others visiting the platforms. The present study fills this gap and aims to increase understanding of how childhood obesity is displayed in social media discussions. This study aims firstly to explore the discussion around childhood obesity in a Finnish discussion forum between parents having a child with obesity and people reacting to the parents. As we will show, the online discussions were for a major part about the reasons for childhood obesity and related solutions and parental roles. Consequently, the second aim of this study was to explore these themes more closely and analyse and interpret the repeating patterns found. Finally, 
in the discussion we consider what additional knowledge our results provide about childhood obesity that can be useful in parents' counselling in health care.

[1] In this article, the term "obesity" incorporates the term "overweight", and the authors are using personfirst language when describing children with overweight or obesity.

\section{Material And Methods}

\section{Discussion forum vauva.fi}

The dataset was acquired from Mohawk, a commercial provider that comprehensively collects and records Finnish social media content. We had access to the discussion threads that have been active during the seven preceding years. To get an overview of the discussion on childhood obesity, we explored all the online discussion forums on the Mohawk database with the search words "childhood obesity". This overview showed that in one online forum, vauva.fi, childhood obesity was discussed more frequently than on other platforms. Consequently, we chose it for our analysis.

In Finland, the vauva.fi (vauva meaning "baby" in English) discussion forum has been one of the most popular forums for years. There are about 7 million visits every month to vauva.fi, and it reaches over 1.5 million people of Finland's 5.5 million population [34]. It is administered by Sanoma Magazine Finland Oy, the publisher of the monthly magazine Vauva and one of the biggest magazine publishers in Europe. The magazine Vauva folded in autumn 2020, but the discussion forum is still alive and active.

Vauva.fi has a reputation as a "funny mum forum", but also as a forum causing bad feelings among discussion participants [35]. Currently, there are 14 discussion headings under Vauva.fi, mostly on children, families, marriage and sexuality. Moreover, the "topic free" heading, is known as a support page for mothers and women, but also for absurd and hilarious discussion openings [34]. All the threads included in this research were found under the "topic free" heading.

On vauva.fi, anyone can read the comments and discussions without registration. One has to register in order to participate in the discussions in most of the headings, the exceptions included the "topic free" heading. The registered members use pseudonyms. The posts are not premoderated on vauva.fi, so the messages are published as they are. However, Sanoma Media Finland Oy delete all the messages that break the law and it can moderate or delete messages that are against good manners.

\section{Data extraction}

The purpose was to locate the relevant online discussion forum and relevant threads discussing childhood obesity, as well as discussions between parents having a child with obesity and other commenters in the forum. The data sampling included several steps (Fig. 1). The data was loaded by using the Mohawk database from the time period of April 2015 - February 2021 (active threads). 
We used the search terms "child obesity" 2, "child overweight" 2, "child weight" 2 (= words were not more than two words apart from each other).

With these search words, in the first phase 111 posts were found in 32 threads. Seven of these threads were deleted by the administration, leaving us with 25 threads. However, the threads contained more posts than the 111 posts found with the search words. We estimated that to get a wide enough picture of the discussions, it was essential to retrieve and read all the other posts of these threads. This was important because in the posts, the use of words is variable and vernacular, and as a result, childhood obesity is not always referred to with any obesity or overweight related word. This led the first author to read all the 15,289 posts of the 25 threads. This allowed us to also cover those posts that did not include the exact words of the initial search.

Next, we eliminated all the posts not covering childhood obesity, such as posts about obesity in general, or posts commenting only specific foods. Finally, to gain an especially parental perspective, we identified posts by parents having a child with obesity and posts reacting to the parents. There were 16 threads where parents have posted, leaving us with a total of 16 threads in the final data.

In this article, we have grouped the commenters into two groups. First, there are those we have identified as parents of children with obesity; they are defined as "parents". To be categorized as a parent required that the person expressed having a child with overweight or obesity, e.g. "My both children are overweight, aged 4 and $5 "$. Even if few of the posts by parents were clearly identified as being posted by a mother and none clearly recognized to be by a father, we named this group parents, as the certainty of the gender was not evident in most of the posts. Secondly, people that were not identified as having a child with obesity, but commented on the parents' posts, we defined as "commenters". In the following analysis, the parents are marked as numbered parents. It was not possible to mark the commenters with separate numbers, because we could not define which posts were written by the same commenters.

In addition, we use the term "obesity" - meaning both obesity and overweight - as we did not have exact information on the weight of the children. This term also makes the text less complex. However, if the commenter was using either word specifically, we used that term in the extracts. As regards the gender of the children, in many cases it could not be specified. This is due to the Finnish language where there are no separate gender-specific pronouns; instead, "hän" refers to both men or boys and women or girls. Consequently, if the child is mentioned in the extract and the gender of the child is not mentioned in the post, the child's pronoun is (s)he.

The length of the posts varied widely, from a few words to over 400 words. The number of posts to parents varied also; some parents did not receive any answers to their posts, whereas some parents received nearly 50 responses. Moreover, the number of parents and other commenters taking part in the threads varied. (Attachment 1).

As regards research ethics in Finland, the present study does not fall under the scope of the Finnish Medical Research Act and Decree (488/1999) [36] and is not guided by its' obligation to ethical review 
and approval by an ethics board. Currently, there is no binding guidelines regarding ethical review of research with social media in Finland, and ethical review in this area is not obligatory at the Tampere University. As regards to Finnish Data Protection Act 1050/2018 [37] and the Copyright Act (404/1961) [38], the posts analysed are anonymous, and general enough in their style and content that it is impossible to connect individual posts to any single individual, and consequently these laws were not applicable here.

We followed the principles of Ethical Decision-Making and Internet [39], the European Code of Conduct for Research Integrity [40] and the ethical principles of research with human participants and ethical review in the human sciences in Finland [41]. In addition, our choices in reporting and research ethics are in line with previous studies in the field such as Appleton, Fowler, and Brown [31] and Kokkonen using the same platform, Vauva.fi [32]. We have carefully applied impact-driven ethics, suitable especially in research with digital media [42]. This implies taking an active role in exploring the possible negative impact of the work for those whose posts we analyse.

The discussion in vauva.fi is public: it is not password protected, it has a large number of registered users, and the posts may be read by anyone. There was no personal identification in the posts, and most of the posts were written under the cybername "visitor". If there was a pseudonym used, we do not report it in the following analysis. With the total anonymity of all commenters, it is clear that the study may not cause harm to the discussion participants.

Due to the anonymity of discussion participants, it was not possible to contact the participants and obtain informed consent. Moreover, the aim of the study was not to analyse individuals who posted on vauva.fi platform, but to analyse the overall themes and styles of posts. On the webpages of the MEXproject (Mediating expertise and scientific knowledge in public debates on health) [43], we have included information on the data used and the e-mail address of the project leader to be contacted in any issues related to the research protocol.

Social media as a research data offers new opportunities for researchers to explore and observe citizens' opinions, activities and interactions in different topics [44]. While analysing social media data, the differences compared to interview data need to be remembered. To start with, the participants of interview studies have been intentionally and with some inclusion criteria recruited to participate, whereas studies utilizing Internet discussion boards do not necessarily involve recruitment of participants, but the participants are those who have themselves chosen to take part in online discussions. Seale et al. [45] have shown that interviewees typically produce retrospective accounts related to the topics of preplanned questions, whereas on the Internet the emphasis is on participants' more current experiences. Finally, on the Internet forums, participants tend to communicate in more intimate ways compared to interviews [45]. Therefore, social media as a research data has potential to provide additional knowledge to various phenomena.

However, with social media data it is difficult for researchers to verify the stories and comments. A part of them might include lies or provocations. Verification is practically impossible with anonymous data, such 
as the posts analysed here. While reading through our data, we kept in mind the possibility on provocations, but identified only two posts where parents might have exaggerated at least a part of their story. For example, one parent stated that "My child's weight is $96 \mathrm{~kg}$. I just feed and feed my obese child. The child does not go outside, does not have any hobby, does not exercise, only watches telly and eats anything unhealthy. I go to grocery 21 times a week. And this is how the child just gains weight." (Parent 46). It was difficult to interpret whether it was a question of parody of a typical image of families with children with obesity, an exaggeration of the situation or true description. Other parents' comments seemed truthful as regards height and weight of the children, and they contained thorough and realistic enough descriptions of the everyday lives of the families. Although two parents aroused doubts about credibility, in the end we decided to keep these parents in the data, because they too were part of the overall tone of argumentation on the platform.

\section{Data analysis}

The posts were analysed with an inductive, thematic analysis. Our aim was not simply to report the occurrence of obesity and components of lifestyle as they are presented in the posts. Instead, our aim was to analyse the posts as social constructions of childhood obesity in social media platform. Thematic analysis is one potential method among qualitative methods enabling the analysis of interpretations and meanings behind the "surface" of the posts [46].

The thematic analysis was conducted following the phases as presented by Braun and Clarke [47]: familiarizing ourselves with the data, generating the initial codes, searching for themes, reviewing the themes, defining and naming the themes, and finally producing the analysis. Regardless, the data process was not linear, rather the process required moving back and forth between phases and a constant return to the data. The inductive method of the coding process allowed the creation of codes and themes that were based on the social media posts by parents and commenters. The final results include three levels: initial codes, sub-themes, and main themes.

When familiarizing ourselves with the data, we wrote down our initial thoughts and observations. After thorough familiarization with the data, the first author identified that a major proportion of the posts was about the reasons and solutions for childhood obesity. Hence, these reasons and solutions were then pinpointed, generating a total of 512 sections of posts where these reasons and solutions were presented. The collected data were then read and re-read several times. In this "repeated reading process" phase [47], nineteen initial codes attached to reasons and solutions for childhood obesity were created (Fig. 2). Some posts included reasons or solutions that fit several codes, and these were categorised in all suitable codes. For example, the following extract was categorised with codes "the character of the child", "the responsibility of the parent", and "healthy lifestyle": "In the afternoons, I can't watch what they eat, but based on the remains, one can eat for example three bananas or five muesli bars at once (you can guess who)" (Parent 41). The initial codes and how they were located in the parents' and commenters' posts are presented in Fig. 2. It should be noted that even though in some initial codes there were occurrences only among the commenters, these comments referred to parents' post related to some other 
theme. So, the commenter could comment with hormone-related comment to a healthy lifestyle related post.

The codes were collected into the same table to find connections between different codes. There, with the posts under the same code grouped together, it was easier to notice the repeated themes in the data. At first, it became clear that there was an emphasis on lifestyle choices, especially heathy or unhealthy eating. But after several returns to codes and the data, we observed a repeated pattern of parenthood and the estimations of its quality across the codes and the posts. This finding led us to create the main themes and the sub-themes. As mentioned, this phase required several returns to the data where the first author pinpointed sections in order to keep the themes reliable and reflect what was expressed in the data. Braun and Clarke call this phase the refinement of the themes.

Once the distinct themes and sub-themes were created, the fifth phase started, which included defining and naming all the themes and sub-themes. In the naming process we considered the themes individually but also as a part of the big picture that emerged from the data. Both authors discussed the names of the themes several times. In the final phase, appropriate examples from the data were chosen to represent the different themes.

Both authors got familiar with the data in all phases. The first author made suggestions in every phase and these suggestions were discussed and modified by both authors several times. If there was any disagreement about the codes or themes, they were discussed and solved to reach a consensus. The data were coded using AtlasTi 9.0, a qualitative data management software programme.

\section{Results}

The commencement of the discussion threads about childhood obesity were often based on some negative news or article from the media, such as "Alarming research: Even children can have fatty liver and high cholesterol - parents do not recognise child's overweight", or written in an accusative tone: "Are parents really so blind that they cannot see the overweight of their own child." Only two of the 16 sampled threads concerning childhood obesity were started by parents. In addition, the number of parents in the threads varied. Eight threads included only one post from a parent. In other threads, more parents took part. For example, when one parent confessed to having a child with obesity, other parents replied sharing the same kind of situation and this led to parents' posts accumulating in the same threads. (Attachment 1).

What followed in the discussions revolved for a good part around the reasons for childhood obesity and related solutions. The reasons and solutions were mostly intertwined in the argumentation, so the presentation of a reason typically also implied a solution and vice versa. Moreover, we found that childhood obesity, and its causes and solutions, were discussed mostly in terms of a healthy lifestyle and in the contexts of parental responsibility and choices. So, when parents and commenters were discussing a healthy lifestyle and obesity, the question of parenthood was at the core of the posts. 
As regards parenthood, we found three main themes: being a good parent, being a bad parent, and being a blameless parent. Each theme contained sub-themes (Table 1). In the following, we will analyse these themes of parenthood and their sub-themes.

The tone of the posts from commenters varied from supportive and counselling to accusing and blaming. However, we found one repeated style of argumentation in all the themes: many commenters were active in giving advice or even commands as to how the parents could or should act. With this style, they were setting themselves above the parents. In the following analysis, we will bring up this argumentation.

Table 1

Main themes and sub-themes in childhood obesity related posts in vauva.fi discussion board.

\begin{tabular}{|ll|}
\hline Main theme & Sub-theme \\
\hline Being a good parent & $\begin{array}{l}\text { Making healthy choices } \\
\text { Making an effort }\end{array}$ \\
\hline Being a bad parent & $\begin{array}{l}\text { Making unhealthy choices } \\
\text { Problems in the family environment }\end{array}$ \\
\hline Being a blameless parent & $\begin{array}{l}\text { Genes, biology, and illness } \\
\text { Circumstances around the family } \\
\text { Child-related factors } \\
\text { Reason unknown }\end{array}$ \\
\hline
\end{tabular}

\section{Being A Good Parent}

A good parent was presented as active, making good lifestyle choices, and trying to change the situation. Comments on lifestyle were mostly in line with the official nutrition guidelines, but there were also some posts that included a different view about a healthy lifestyle, such as the strict restriction of bread or other carbohydrate sources. We found two ways of presenting a good parent: making healthy choices and making an effort.

\section{Making healthy choices}

It was very common - mostly by parents, but also by some other commenters - to post about various things that they have done "right" in their everyday life. In the discussions, a good parent was seen as a parent who is active in making healthy choices and avoiding unhealthy choices in the child's everyday life. Parents attempted to convince others that they have made healthy choices despite the child's obesity and listed the things they had already done - mainly relating to eating or exercise. Parents tried to reassure other participants in the threads that they had done things that a good parent would do, and 
some of the parents even listed their everyday eating. Parents did recognise the importance of a healthy lifestyle, but often felt they had done all they could already.

We do not go in for biscuits, cakes, and buns, nor do we drink juice every day. They do not drink sodas and [eat] chips, etc. they get those maybe 5 times a year. They exercise actively every day. (Parent 14)

Another way that the parents expressed themselves as doing things right was by explaining that other family members were of normal weight, meaning that the reason for one child's obesity could not be in the way the parents handle everyday life in the family. Other children in the family were proof of good parenthood. These statements by parents were often surrounded by lists of what parents were performing well.

If just someone would find out the reason for gaining weight? We have four children, and only one of them is overweight. The whole family eats the same food and has the same habits with snacks. This child has no extra money to buy any additional food or snacks. (Parent 15)

A few commenters listed reasons why there were no weight issues in their families. These reasons and related solutions included healthy choices and right ways to raise a child. The commenters presented themselves as successful, good parents, setting an example to other parents of how things should be done.

I have an 8-year-old and two other children. No-one lies the whole day with a mobile, they go out every day, because I make them, and they do not buy candy from the grocery store without permission, because I don't give them money for that. And this is why their bellies do not grow. (Commenter)

\section{Making an effort}

Another way of presenting good parenthood was showing one's effort-making, trying one's best to make things better, even when these efforts did not bring results. Parents explained the efforts they had made, assuring that they had put time and effort into trying to fix the situation. If the child was obese, a good parent was presented in the discussions as someone who is actively seeking a solution and is ready to ask and receive advice.

I can even make a vow that we have done more than many others for the welfare of our children. (Parent 31)

Moreover, the commenters pushed and advised the parents to make an effort or ask for advice on how to manage the child's weight. Parents did recognise the importance of a healthy lifestyle but felt often that they had already done all they could. Alternatively, some parents had reason why they could not implement sufficiently healthy choices in their own or their child's everyday life. Parents did not bring up parental responsibility as often as the other commenters did. Parents' reports about how they had changed or tried to change things in their lifestyle, indicate that they recognised their influence on the child's everyday life. Parents wanted to present themselves as active parents who were trying their best. 
Simultaneously, the commenters were expecting the parents to try harder to change the lifestyles of the family.

\section{Being A Bad Parent}

Another way of framing reasons and solutions for childhood obesity was defining parents as unsuccessful and performing bad parenthood. Bad parenting was presented in two ways: first, by presenting parents as feeding the child unhealthy food or not offering enough healthy choices, and secondly, by focusing on the problems in the environment of the family and the parents' inability to respond to the child's emotional needs in the correct way.

\section{Making unhealthy choices}

Commenters brought up lifestyle factors frequently by listing what parents should or should not do or what lifestyle factors will produce obesity. Commenters were active in sharing knowledge and advice on how to eat healthily and to raise healthy children. In these statements, there was a presumption that parents having a child with obesity were doing something wrong, especially offering unhealthy choices and not being assertive enough.

You should change the hard fats for soft fats, add vegetables/berries/fruits, eat according to the plate model, emphasising vegetables, eat less sugar and white wheat, change the pasta, bread, porridge to wholewheat products, eat less meat and prefer a more vegetable-rich diet. These things will get you forward. I suppose you cook food at home, so it should not be too much effort to make these changes. No one else is doing these changes, it is easy to make excuses. (Commenter)

This answer (referring to the post of one parent) sums up what is wrong in Finnish families. It is the lack of parental authority. An eight-year-old wants to lay down and stare at a mobile. And they LET the child do this, how can this be possible? (Commenter)

In one discussion thread, a parent started defending her situation fiercely and commenters tried to point out mistakes the parent had made. When this parent continued to defend herself and challenged other posts, the commenters became more aggressive, suggesting that the parent was to blame and was a bad parent. In the end, the commenters disregarded the parent and addressed their posts to other commenters.

Do others see how this one mother is defending her actions, even though the son is clearly morbidly obese? And how annoying is it, when such a reasonable discussion is filled up with this mother's defensive talk? She really does not seem to believe that her child is in bad shape and is defending herself by lifting herself and her "fancy home cooking" onto a pedestal. (Commenter)

I think this one mother knows that she is at least partly to blame for her son's considerable overweight. Otherwise, nobody would so fiercly and all the time come here to defend their situation. Your son has to 
lose weight significantly to have a healthy life. (Commenter)

It was very rare for parents to confess that they had done things wrongly. In these few posts, parents expressed guilt and shame and felt responsible for the child's obesity.

I feel guilty that I let my son gain weight. (Parent 29)

I don't get it why I really have not noticed this (child's obesity) before. The school nurse said last autumn that we are going into the upper limits of the growth charts and the family should look at what it eats. The girl is 12 years old. She likes sugary stuff; I have tried to limit it. But she eats up to three plates of even basic food. How can I deny her when she is saying that otherwise she will stay hungry? Damn, I have been a bad mother. (Parent 53)

\section{Problems in the family environment}

Another way of presenting bad parenthood was by pointing out that the parents were creating a harmful family environment. Commenters suspected that the child's obesity or eating was only a symptom of something else, such as depression, teasing, or simply boredom, and it was a parental responsibility to prevent the child from compensating for emotional needs with food. Again, the commenters made assumptions that parents are to blame by not meeting the emotional needs of the children. The commenters addressed questions, offered advice, and made accusations regarding the family's environment.

A healthy relationship to eating comes when eating in the child's environment is healthy. If there are feeling-eaters around showing a model of vomiting-eating, that does not provide a healthy model for learning. (Commenter)

Have you offered your son anything else than food? Experiences, hobbies, being together, experiences in succeeding? Pleasures without food? Usually, if there is meaningfulness and passion in life, it can be anything from playing drums, dinosaurs, to camping, one does not need to binge oneself into a ball. Because then the food is in that situation where it belongs, and the meaning of life comes from somewhere else than the daily chocolate bar or ham sandwiches. (Commenter)

The extract below reveals the negotiation between the parents' responsibility for their children and factors behind obesity that the parents should control. The commenter aims to bring up parental responsibility and not hide behind fatalistic explanations.

The point is that "the child is only greedy for delicacies" is often a simplified excuse for a situation where there are bigger problems in the background. Adults are easily blind to these, because they do not want to see the bad feelings of their own child. (Commenter)

Parents presented hurt and anger when they replied to posts where they were accused of being incapable parents unable to create a supportive and balanced environment for the child. Sometimes, like the mother 
below, the parent defended herself fiercely, but mostly parents did not react to accusative posts regarding the inability to fulfil the child's emotional needs.

Honestly, I feel disgusting when you paint a picture in which my son is some kind of filthy and mentally bored outcast and us parents are people who have abandoned their child. (Parent 31)

\section{Being A Blameless Parent}

Finally, the reasons and solutions for childhood obesity were presented as being out of the parents' control and hence the parents were blameless for the situation. Here, the parent was seen as being more of a victim in the situation, not the guilty party. There are reasons that parents cannot avoid, even if they wanted or tried, as well as solutions that are not dependent on the parents' actions. Among the parents, the blameless parent theme went hand in hand with being a good parent: often parents firstly listed things that they had already tried or done and following this was a statement that they would do more if there were any solutions left. The parents used the blameless parent arguments more often, but commenters also gave absolution to parents when expressing reasons and solutions that were not seen as the parents' fault.

\section{Genes, biology, and illness}

Both parents and commenters acknowledged there were factors behind childhood obesity that are hereditary, genetic, or caused by a hefty body size or an illness, such as a slow metabolism. Specific or hidden illnesses, genes, and hormones were mentioned as reasons for children's obesity. Situations such as the mother not eating sufficiently during pregnancy or either breastfeeding too much or not breastfeeding at all were presented as reasons, too. Factors attached to pregnancy or breastfeeding included aspects that could also be interpreted as bad parenting. However, here we categorised these accounts as examples of blameless parents, as especially parents presented these issues as something that they could not have changed in their current situation.

Children from the same family, eating the same food, can become different in body shape because of their genes. (Commenter)

There have been inspections for years and $s / h e$ is medicated constantly. The weight is the only thing that is apparent outside, even though s/he has also other problems, even more severe, caused by this illness. (Parent 32)

My child was born big and gained weight from long breastfeeding. My milk was like cream. (Parent 49)

Even though some commenters identified these factors as mostly outside the parents' influence, they nevertheless often offered advice on a healthy lifestyle. 
If Prader-Will is excluded, then this could include a condition caused by fructose, in which saturation hormones and peptides do not affect the brain. Leave out the sugar and see if the situation levels out. (Commenter)

Some parents had a situation where the child became obese after reversing underweight. The parents felt that the previous underweight was the reason behind the obesity, and often the concern about the child not having enough food led to a situation where the child got used to big portions and favourite meals.

And then suddenly everything turned upside down. The girl started to eat everything, even too much. We did not prevent this, while we remembered this skeleton-thin girl, and if she now wanted 7 meat balls and two bread rolls, she was allowed to eat them. If she wanted a third bowl of cereal, she got it. (Parent 6 )

Moreover, some parents and commenters were setting their hopes on future height growth that would solve the obesity problem, as shown in the extracts bellow. The commenters shared experiences when their own weight was normalised during height growth. Interestingly, commenter bellow is combining the height growth argument with the healthier habits argument, suggesting that one should not rely only on height growth as a solution.

I believe that the child is collecting her/his energy storage for growth. The feet grew already three sizes in the summer, so the height growth will be next soon. (Parent 27)

When moving to healthier habits, height growth usually deletes the child's overweight. (Commenter)

\section{Circumstances around the family}

While most of the posts presented either reasons under parental control or biological reasons outside parental control, also external reasons and solutions related to the surrounding society or social networks were presented by both parents and commenters. These were presented in a way that there are attributions to childhood obesity outside the family and as outside parental control.

Public institutions, such as child healthcare clinics and day care, were seen both as a reason for and a solution to childhood obesity, both among parents and commenters. A good example of this is a lengthy thread where one parent suspected day care food to be the reason for her child's obesity.

Both my children are overweight, aged 4 and 5 . They started gaining weight when they started at kindergarten and the consumption of bread and sugar bounced up significantly. In the kindergarten, they also swear by fat-free milk products. (Parent 14)

The parent above received mostly disagreeing posts about blaming the day care, but also some posts agreeing that the day care was the reason for the obesity. In other threads, child welfare clinics and other experts were mentioned a few times as solutions for childhood obesity and mainly as places to seek help and advice. There were also posts expressing a wish to receive support from experts in health care. In the following extract, the commenter is optimistic about the help from the child welfare clinic, whereas the parent below is more sceptical. 
You should ask for help from the child welfare clinic to make food portion sizes correct. (Commenter)

In child welfare clinics, weight management issues are quite poorly taken care of. With my slightly chubby child, the advice was to add vegetables and use non-fat milk. (Parent 8)

Grandparents were also mentioned as a reason for the child's obesity in several posts, mostly in one thread. These were mainly responses to one parent who complained that their child was obese due to the grandparents' treats. Some commenters questioned this explanation, whereas others supported it and shared similar experiences. In the next extract, one commenter shares similar experiences with her mother.

My mom was the same with me and now she is also trying to fatten my own child. She just does not understand for some reason that you cannot take a bun or cake with coffee every day or maybe an adult can, but with a small child, it will definitely lead to a sugar spiral. (Commenter)

A few comments were made also about the environmental influence on the child's weight, such as chemicals and microplastics, Teflon pans, cosmetics, antibiotics, and intestinal flora.

\section{Child-related factors}

There were several posts that presented a certain characteristic of the child as the reason for obesity, for example the child's habit of overeating or preference for inactivity. In contrast to the previously presented theme of genes as a reason for obesity, here child-related elements included those concerning the child's behaviour. Both parents and commenters made observations that some children had more challenging characters that can cause obesity. Parents gave examples about their child's character and commenters about families near them, and there were supportive and defending posts that these situations are challenging and hard for parents.

While children are different. In my friend's family, one child is chubby, two others are normal weight, even slim and sporty. There is a healthy lifestyle in this family, but this chubby child has a huge appetite for treats. I have noticed this when the child is visiting our home. At parties, this child hogs treats above everybody else, eats double the amount of food compared to others, etc. (S)he is lazy and does not like to exercise. This family, I think, has a very normal attitude towards food, treats are not a forbidden fruit, but if they are offered without limits, this one child would eat them without end. (Commenter)

Some parents identified that their child's energy intake was too high, but they were unsure how to solve the situation, mainly because the child's appetite was huge, and they did not want the child to suffer from hunger. Parents felt that they could not prevent or solve this. The following question on the child's weight by a parent includes a suggestion that the obesity is perhaps related to some innate characteristics that the parent cannot change:

What can one do when the child is really reluctant to drink enough water, (s)he has a huge appetite, and is very greedy for sugary treats? Age 11, so (s)he is eating also in other places besides the home. (Parent 3 ) 
The following parent brought up several unhealthy lifestyle components that they were unable to change because the child was reluctant to make them.

How do I force that 11-year-old out for a run, when he does not want to? The rest of the family cycles to the playground or takes a walk in the forest, but this first-born stays at home on the couch with his cell phone. And every now and then goes to look for something to eat from the fridge. He is keen on snacks, but also loves bread, which s/he can eat a bag a day. Probably also buys snacks secretly from the shop. Someone will ask where the money comes from, but for example, liquorice candy costs only 30 cents a piece. (Parent 5)

Interestingly, an obesogenic environment - such as the supply of energy-intense food or an environment that does not encourage exercise, played no significant role in the posts. If a passivating environment or energy-dense products were mentioned, it was presented as a challenge that should be solved by the parents or child. The problem was not the environment, but the parent or the child.

\section{Reason unknown}

Commenters had always a reason or solution - or at least a suggestion - for the child's obesity, but several parents expressed a genuine lack of understanding why their child was obese. If the reason was a mystery, despite the effort to solve the problem, there was nothing that a parent felt that could be done. This ignorance was visible when one child's obesity was set in the context of other children's normal weight, as in the following extract:

Not a single public health nurse nor doctor nor dietitian has come up with a reason why there are two slim children and one overweight in our family. We all eat the same food and there are sporty hobbies. (Parent 36)

Another way of presenting ignorance was listing various typical reasons behind obesity, and stating that none of the listed reasons applied to their situation and hence could not be used as solutions for their child's obesity, as the following parent presents:

We eat normal home-cooked food (e.g. macaroni casserole and salad, water to drink with food), and when younger, he had a candy day. We do not purchase juice or soda! Still the boy has gone above the weight limits, big time. Tests have been taken, but no illness has been found that would explain this. (Parent 44)

When parents explained that the reason for the child's obesity was a mystery, commenters again offered additional solutions and advice, mostly to do with eating or exercise habits. Usually, parents did not reply to these posts, but if they did, and especially if they defended their choices, the commenters easily became more accusing.

\section{Discussion}


The aim of this research was to explore Finnish social media discussion forum Vauva.fi to identify, analyse and interpret discussions about childhood obesity. Our study focused on posts by the parents of children with obesity and other commenters' replies to these parents. We have shown that childhood obesity and its causes and solutions were discussed mostly in the context of parental responsibility, the quality of parenthood and a healthy lifestyle. We found three main themes that were used to define parenthood: being a good parent, being a bad parent, and being a blameless parent.

The overall tendency in the posts was to associate good parenthood with healthy lifestyle of the family and consequently, lack of obesity among the children. Our findings revealed that proving one's good parenthood is a core issue among parents having a child with obesity. A similar phenomenon was found in a study of parents of ill children: a good parent expresses both a personal sense of duty and devotion [48]. Parenting websites more broadly, too, are often places where mothers define, strengthen, or re-work the ideal of the good mother [49].

Besides descriptions of good parenthood, the danger of being a bad part was clear in the posts analysed here. As regards bad parenting, the commenters of our data provided a contrast to the parents' posts, bringing up the theme of bad parenting - only two of the parents stated that they were themselves bad parents. A previous study of social media discussions of childhood obesity by Kokkonen (2009) showed, that parents were mainly viewed as the primary cause of the child's overweight, and they were presented as having poor parental abilities [32]. Nnyanzi et al., too, have reported that parents with normal-weight children view other parents - especially those whose children had weight problems - as not doing things correctly [50]. Pulling together the themes of good and bad parenting, we conclude that our results reflect the cultural ethos where children with obesity are seen to signify parental failure and neglectful caring, especially by mothers [51,52], and where the weight of one's child has become "litmus test of good mothering" [53].

On another level, the themes above reveal the strong tendency of modern societies to put emphasis on individual's responsibility in health issues. Robert Crawford, for example, has pointed out that in recent decades in Western societies, there has been heightened concern about health issues from an individualistic perspective [54]. Individual-centred explanations for obesity have been reported among people taking part in lifestyle change interventions [55], among health care professionals [56] and among children [57]. Moreover, the centrality of lifestyle choices in our results is not a surprise, considering the way in which in the Western media, including in Finland, obesity is presented as a result of unhealthy lifestyles of individuals, especially a result of unhealthy diet [19, 20, 58].

In the case of childhood obesity, Gard and Wright (2005) show that in Western media obese children are typically portrayed as lazy coach potatoes who along with their parents, should participate in the 'war on obesity' [20]. On Twitter, childhood obesity was more often presented as a question of individual behaviour than as a question of environment or policy [59]. Results from many countries reveal similar results: Boero (2009), has brought up the tone of reporting on childhood obesity in the US media as putting the blame on mothers [53]. An analysis of American and Canadian parenting magazines showed 
that from the 1980s onwards parents have been advised to get their child eat more healthy food and less junk food, get more exercise and be less sedentary Interestingly, since the early 2000s the advice has become more detailed requiring a great deal of more effort for the parents [60]. In UK print media, childhood obesity was related to individual-level drivers and solutions more frequently than societal-level drivers. Finally, in the parenting advice for childhood obesity in the UK news media, individual parents, usually mothers, were presented as responsible for their child's health and weight [61].

The third way of defining parenthood - the blameless parent - diverged from the strong tendency to define parenthood by the lifestyle habits of the family. One type of blameless parenthood was present in posts where parents expressed confusion and desperation over situations in which the child was obese despite their good intentions and healthy habits in the family. Various genetic and medical factors were brought up, as well as the role of social environment in the descriptions of foods, meal patterns, snacking and use of mobile phones. Some parents stated that they simply do not know the reason for their child's obesity. This reflects the realities of what has been termed obesogenic environment [5] - there are so many co-existing causes that it is impossible to pinpoint one single cause for the obesity of one's child.

Here good parenthood did not actualise despite the actions and activity, especially in terms of healthy habits. Among the parents studied by Syrad et al., weight was occasionally attributed to "inherited factors", such as genetics or puppy fat [15] - resembling the theme of blameless parent of our study. In our results, some parents and commenters held the view that the child's personality might be the reason behind obesity and consequently, the parents are incapable of solving the situation. Another study found similar results: mothers felt that one reason why they were not able to provide healthy food for the child was because the child had special needs or food preferences [62].

To conclude, in addition to the strong emphasis on the individual responsibility of the good and bad parenthood themes, in the blameless parenthood theme individual responsibility was difficult to perform. Together these themes and the sub-themes of our results represent the multifactorial nature of childhood obesity. Many of the genetic, psychosocial and lifestyle-related causes of obesity have also frequently been presented in Finnish media, too. It is probable that parents and commentators had picked up their rationalizations at least partly from news media.

We did not find however, overt criticism of neoliberal societies or consumer capitalism, that has been judged by some scholars as the main culprit for the negative stigmatization of the obesity $[19,63]$ and for the current food environment behind obesity. Another perspective we did not observe, but that has been recently increasingly present in news media and social media, is the promotion of "body positivity" and "fat acceptance". Some studies suggest that a change might be gradually happening: in recent years, more versatile advice for parents has appeared in North American media, such as protecting body image [60]. Moreover, in Finland among many other Western countries, body positivity has been increasingly visible in print media, television, and social media [64-66]. If the news media continues to present more diverse perspectives on obesity, the cultural conceptions of obesity might change gradually, impacting also social media discussion forums. 


\section{Limitations And Strengths}

Anonymous social media data have their limitations and strengths. There is no way of verifying or clarifying the stories in the posts, and some of the commentors might be written with tongue in cheek. In addition, the absence of facial expressions and body gestures makes it more difficult to interpret the posts correctly, especially if there was sarcasm. However, on anonymous Internet forums, some participants may communicate in more intimate ways their difficulties, compared to face-to-face interviews or observing encounters in health care.

We concluded that it is possible that the posts of two parents were either provocations or at least exaggerations. Hence, a clear majority of the data was trustworthy. To further evaluate the reliability of our results we compared them to other studies on the same topic. As already brought up in the discussion above, our results are in line with previous research on perceptions of childhood obesity among parents, utilizing online discussion forum data $[10,31,32]$ and with qualitative research conducted with interviews among parents $[15,50,62]$. To further validate our results, we compared them with studies based on focus group discussions: Vietnamese mothers brought up similar ways of managing child's weight as did the parents of our data - controlling food intake, increasing physical activity and encouraging child's selfcontrol [67]. Chinese parents, too, had difficulties in controlling dietary intake or increasing physical activity of their children [68]. Australian parents reported frustrations, and related need of support to better guide their child's eating, screen-time and sleeping patterns [69]. Similar frustrations were brought up by our parents of this research, especially when they also reported ignorance of the reason for the overweight. Lastly, among American parents, the child's dietary or activity preferences were seen an obstacle to the parents' efforts to guarantee the child's healthy diet [11]. This phenomenon was also present in our results, for example in the theme emphasizing the blamelessness of parents. To conclude, similar topics and themes have been brought up with different qualitative research methods.

The present research adds to the understanding of perceptions of childhood obesity by demonstrating the discussion and interaction between parents and other commentators in the online discussion forum. Analysis of Internet forums has a value of its own. Many parents read online discussions and hence, are affected by the ways of commenting obesity and parenthood there. Additionally, Internet forums are not separate from the lives elsewhere, and consequently, they reflect the broad attitudes towards obesity in our cultures. By knowing the cultural conceptions parents confront on online forums, health care professionals may gain insights into how to understand parents' reactions better.

The strength of this research is that the data focused on parents, and hence we offer insights into parents' perceptions of childhood obesity. In addition, by including posts by other commenters, we were able to analyse more broadly the attitudes towards families with children with obesity. This helps in understanding parents' reactions to health care counselling on this sensitive issue, childhood obesity.

\section{Conclusions For Health Care}


Several parents in our study expressed they were living under the critical gaze of others. Moreover, commenters frequently implied that the parents were not good enough or not trying hard enough to fulfil the criteria of good parenthood. As has been shown by a systematic review, judgement and shame form a part of the lives of people with obesity [70]. We also found a similar phenomenon in relation to children's weight, and many parents felt stigmatised as having failed in the task of parenthood. Experiences of stigmatisation can in turn influence the willingness to seek help and support services [22]. Consequently, health care professionals need to be careful not to increase the stigmatisation of these parents. One way to avoid it could be to preserve and reinforce the experience of being a good enough parent. In addition, health care professionals should reframe the discussion to deconstruct the stigma of obesity and emphasise inclusive, affirmative, and health-focused messages [71].

When parents bring up reasons for obesity outside their influence, placing themselves as victims in the situation, traditional, well-intentioned lifestyle counselling might not be the help parents seek. In these situations, new aspects and openings are needed for the health care discussions over a child's weight. Instead of being "educated" in healthy lifestyle behaviours, parents want strategies and support to deal with the frustrations of food, screen, and sleep parenting [69]. Parents need more tools to handle a child that has a huge appetite, ration the use of snacks, and deal with other unhealthy behaviours. Some parents might also benefit from tools and advice to handle a child with special needs or in families where lifestyle routines repeatedly create tensions. One tool worth exploring could be The Lifestyle Behavior Checklist (LBC), which was developed to assess parents' perceptions of the child's obesity-related behaviours and the parents' self-efficacy to deal with the situation [72]. It would be beneficial to find alternatives to weight measuring, to help parents to see the progress, for example in eating related perceptions or every-day choices. In addition, instead of giving advice, promoting positive relationships between parents and children holds much promise as a component of efforts to prevent childhood obesity [73]. The health care worker's ability to receive and accept the parents' emotions and offer support for parental skills could help parents to cope in the present situation with the child's weight and hence develop counselling in a more family-focused direction.

\section{Declarations}

\section{Acknowledgements}

We would like to thank the Academy of Finland for funding the research (grant nr: 320279).

\section{Authors' contributions}

TK collected and analysed data and drafted and revised the manuscript. PJ provided critical direction in the study's conceptualisation, investigation and methodology, and supported the revision of the manuscript. All authors read and approved the final manuscript.

\section{Availability of data and materials}


All posts used for the analysis are available from the corresponding author upon request. The database Mohawk is a commercial provider that comprehensively collects and records Finnish social media content and is only available for customers. The vauva.fi discussion board Vauva.fi is public accessed, it is not password protected and the posts may be read by anyone. https://www.vauva.fi/

\section{Competing interests}

The authors declare that they have no competing interests.

\section{Consent for publication}

Not applicable.

\section{Ethics approval and consent to participate}

As regards research ethics and related legislation in Finland, the present study does not fall under the scope of the Finnish Medical Research Act and Decree (488/1999), as our research does not include medical research. Consequently, the research is not guided by its' obligation to review and approve by an ethics board. As regards to the Finnish Data Protection Act 1050/2018 and the Copyright Act (404/1961), the posts analysed here are anonymous and general enough in their style and content, that it is impossible to connect individual posts to any single individual. Consequently, neither these Acts were not applicable here. Currently, there is no law or guideline concerning anonymous social media data in research. Due to the lack of national regulations on social media data in Finland, ethical review was determined as not compulsory.

It was not possible to contact the individuals whose posts were included in the study since they were all anonymous users on the platform. Consequently, it was impossible to obtain informed consent. Due to the total anonymity and the fact that the vauva.fi platform is public and not password protected and has a very large number of posts and commenters every day, it is evident that the study may not lead to identification of any single commenter and consequently cause harm to the discussion participants. Therefore, ethical review was determined as not providing significant backup for the ethicality of the research.

\section{Funding}

This work was funded by the Academy of Finland (nr: 320279).

\section{References}

1. World Health Organization. Obesity and overweight. 2021. https://www.who.int/news-room/factsheets/detail/obesity-and-overweight Accessed 20 Jul 2021.

2. Terveyden ja hyvinvoinnin laitos. Lasten ja nuorten ylipaino ja lihavuus. 2020. https://thl.fi/fi/tilastotja-data/tilastot-aiheittain/lapset-nuoret-ja-perheet/lasten-ja-nuorten-ylipaino-ja-lihavuus Accessed 11 
Nov 2021.

3. Reilly JJ, Kelly J. Long-term impact of overweight and obesity in childhood and adolescence on morbidity and premature mortality in adulthood: systematic review. Int J Obesity. 2011;35:891-8.

4. Barlow SE, and the Expert Committee. Expert Committee Recommendations Regarding the Prevention, Assessment, and Treatment of Child and Adolescent Overweight and Obesity: Summary Report. Pediatrics. 2007;120 Supplement_4:S164-92.

5. Hill JO, Peters JC. Environmental Contributions to the Obesity Epidemic. Science. 1998;280:1371-4.

6. Anderson PM, Butcher KF (Kristin F. Childhood Obesity: Trends and Potential Causes. Future Child. 2006;16:19-45.

7. Ebbeling CB, Pawlak DB, Ludwig DS. Childhood obesity: public-health crisis, common sense cure. The Lancet. 2002;360:473-82.

8. Newson L, Povey R, Casson A, Grogan S. The experiences and understandings of obesity: Families' decisions to attend a childhood obesity intervention. Psychol Health. 2013;28:1287-305.

9. Lucas PJ, Curtis-Tyler K, Arai L, Stapley S, Fagg J, Roberts H. What works in practice: user and provider perspectives on the acceptability, affordability, implementation, and impact of a familybased intervention for child overweight and obesity delivered at scale. BMC Public Health. 2014;14:614

10. Appleton J, Fowler C, Brown N. Parents' views on childhood obesity: qualitative analysis of discussion board postings. Contemp Nurse. 2017;53:410-20.

11. Styles JL, Meier A, Sutherland LA, Campbell MK. Parents' and Caregivers' Concerns About Obesity in Young Children: A Qualitative Study. Fam Community Health. 2007;30:279-95.

12. Toftemo I, Glavin K, Lagerløv P. Parents' views and experiences when their preschool child is identified as overweight: a qualitative study in primary care. Fam Pract. 2013;30:719-23.

13. Falconer CL, Park MH, Croker H, Skow Á, Black J, Saxena S, et al. The benefits and harms of providing parents with weight feedback as part of the national child measurement programme: A prospective cohort study. BMC Public Health. 2014;14:549.

14. Etelson D, Brand DA, Patrick PA, Shirali A. Childhood Obesity: Do Parents Recognize This Health Risk? Obes Res. 2003;11:1362-8.

15. Syrad H, Falconer C, Cooke L, Saxena S, Kessel AS, Viner R, et al. "Health and happiness is more important than weight": a qualitative investigation of the views of parents receiving written feedback on their child's weight as part of the National Child Measurement Programme. J Hum Nutr Diet. 2015;28:47-55.

16. Park MH, Falconer CL, Saxena S, Kessel AS, Croker H, Skow Á, et al. Perceptions of health risk among parents of overweight children: A cross-sectional study within a cohort. Prev Med. 2013;57:55-9.

17. Turner KM, Salisbury C, Shield JPH. Parents' views and experiences of childhood obesity management in primary care: A qualitative study. Fam Pract. 2012;29:476-81. 
18. Bentley F, Swift JA, Cook R, Redsell SA. "I would rather be told than not know" - A qualitative study exploring parental views on identifying the future risk of childhood overweight and obesity during infancy. BMC Public Health. 2017;17:684.

19. Harjunen H. Neoliberal bodies and the gendered fat body. London; Routledge Taylor \& Francis Group; 2017.

20. Gard Michael, Wright Jan. The obesity epidemic: science, morality and ideology. London: Routledge; 2005.

21. Monaghan LF, Rich E, Bombak AE. Rethinking obesity: critical perspectives in crisis times. Milton Park, Abingdon, Oxon; New York, NY: Routledge; 2022.

22. Pont SJ, Puhl R, Cook SR, Slusser W, Bolling CF, Armstrong S, et al. Stigma experienced by children and adolescents with obesity. Pediatrics. 2017;140:e20173034.

23. Puhl RM, King KM. Weight discrimination and bullying. Best Practice \& Research Clinical Endocrinology \& Metabolism. 2013;27:117-27.

24. Davis JL, Goar C, Manago B, Reidinger B. Distribution and disavowal: Managing the parental stigma of Children's weight and weight loss. Soc Sci Med. 2018;219: 61-9.

25. Zenlea IS, Thompson B, Fierheller D, Green J, Ulloa C, Wills A, et al. Walking in the shoes of caregivers of children with obesity: supporting caregivers in paediatric weight management. Clinical obesity. 2017;7:300-6.

26. Tanis M. Health-Related On-Line Forums: What's the Big Attraction? J Health Commun. 2008;13:698-714.

27. Ruckenstein M, Schüll ND. The Datafication of Health. Annu Rev Anthropol. 2017;46:261-78.

28. Tilastokeskus. Internetin käyttö medioiden seuraamiseen ja viestintään lisääntynyt. 2020. https://www.stat.fi/til/sutivi/2020/sutivi_2020_2020-11-10_tie_001_fi.html Accessed 20 Apr 2021.

29. Baker S, Sanders MR, Morawska A. Who Uses Online Parenting Support? A Cross-Sectional Survey Exploring Australian Parents' Internet Use for Parenting. J Child Fam Stud. 2017;26:916-27.

30. Berger M, Wagner TH, Baker LC. Internet use and stigmatized illness. Social Science \& Medicine. 2005;61:1821-7.

31. Appleton J, Fowler C, Brown N. Friend or foe? An exploratory study of Australian parents' use of asynchronous discussion boards in childhood obesity. Collegian. 2014;21:151-8.

32. Kokkonen R. The fat child-a sign of 'bad' motherhood? An analysis of explanations for children's fatness on a Finnish website. Journal of community \& applied social psychology. 2009;19:336-47.

33. Chou WS, Prestin A, Kunath S. Obesity in social media: a mixed methods analysis. Trans Beh Med. 2014;4:314-23.

34. Sonia El Kamel. Mikä on synnytyslakki, entä pesetkö jauhelihan ennen kypsennystä? - Vauva.fi:n legendaarisia keskusteluja koottiin kirjaksi. Helsingin Sanomat. 2018. https://www.hs.fi/kulttuuri/art2000005870361.html Accessed 20 Apr 2021. 
35. Vaahensalo E. Keskustelufoorumit mediainhokkeina - Suositut suomenkieliset keskustelufoorumit mediassa. Widerscreen. 2018, 3(21). http://widerscreen.fi/numerot/2018-3/keskustelufoorumitmediainhokkeina-suositut-suomenkieliset-keskustelufoorumit-mediassa/

36. Laki lääketieteellisestä tutkimuksesta 488/1999. https://www.finlex.fi/fi/laki/smur/1999/19990488 Accessed 4 Feb 2022

37. Tietosuojalaki 1050/2018. https://www.finlex.fi/fi/laki/smur/2018/20181050 Accessed 4 Feb 2022.

38. Tekijänoikeuslaki 404/1961. https://www.finlex.fi/fi/laki/smur/1961/19610404 Accessed 4 Feb 2022.

39. Markham AN, Buchanan EA. Internet Research: Ethical Concerns. In: International Encyclopedia of the Social \& Behavioral Sciences. Second Edition. Elsevier Ltd; 2015. p. 606-13.

40. Hosseini M, Lewis J. The norms of authorship credit: Challenging the definition of authorship in The European Code of Conduct for Research Integrity. Accountability in Research. 2020;27:80-98.

41. Finnish National Board on Research Integrity TENK guidelines 2019. The ethical principles of research with human participants and ethical review in the human sciences in Finland. 2009.

42. Markham AN. Afterword: Ethics as Impact-Moving From Error-Avoidance and Concept-Driven Models to a Future-Oriented Approach. Social media + society. 2018;4:205630511878450.

43. Nutrition, expertise and media - MEX. https://research.tuni.fi/piiajallinoja/projektit/mex-hanke/. Accessed 20 May 2022.

44. Zimmer M, Kinder-Kurlanda K. Internet research ethics for the social age: new challenges, cases, and contexts. New York: Peter Lang; 2017.

45. Seale C, Charteris-Black J, MacFarlane A, McPherson A. Interviews and Internet Forums: A Comparison of Two Sources of Qualitative Data. Qual Health Res. 2012;20:d1e155435a1048964606.

46. Braun V, Clarke V. Thematic analysis: a practical guide to understanding and doing. 1 st edition. Thousand Oaks: SAGE Publications; 2021.

47. Braun V, Clarke V. Using thematic analysis in psychology. Qualitative research in psychology. 2006;3:77-101.

48. Weaver MS, October T, October T, Feudtner C, Feudtner C, Hinds PS, et al. "Good-Parent Beliefs": Research, concept, and clinical practice. Pediatrics. 2020;145:e20194018.

49. Pedersen S. The good, the bad and the 'good enough' mother on the UK parenting forum Mumsnet. Women Stud Int Forum. 2016;59 Journal Article:32-8.

50. Nnyanzi LA, Summerbell CD, Ells L, Shucksmith J. Parental response to a letter reporting child overweight measured as part of a routine national programme in England: results from interviews with parents. BMC Public Health. 2016;16:846.

51. Coveney J. The government of girth. Health Sociology Review. 2008;17:199-213.

52. Friedman M. Mother Blame, Fat Shame, and Moral Panic: "Obesity" and Child Welfare. Fat Studies. 2015;4:14-27. 
53. Boero N. Fat Kids, Working Moms, and the "Epidemic of Obesity": Race, Class, and Mother Blame. NYU Press; 2009. p. 113-9.

54. Crawford R. Health as a meaningful social practice. Health. 2006;10:401-20.

55. Jallinoja P, Pajari P, Absetz P. Repertoires of lifestyle change and self-responsibility among participants in an intervention to prevent type 2 diabetes. Scand J Caring Sci. 2008;22:455-62.

56. Zelenytė V, Valius L, Domeikienè A, Gudaitytė R, Endzinas Ž, Šumskas L, et al. Body size perception, knowledge about obesity and factors associated with lifestyle change among patients, health care professionals and public health experts. BMC Fam Pract. 2021;22:37.

57. Rees R, Oliver K, Woodman J, Thomas J. The views of young children in the UK about obesity, body size, shape and weight: a systematic review. BMC Public Health. 2011;11:188.

58. Kim S-H, Anne Willis L. Talking about Obesity: News Framing of Who Is Responsible for Causing and Fixing the Problem. J Health Commun. 2007;12:359-76.

59. Harris JK, Moreland-Russell S, Tabak RG, Ruhr LR. Communication about childhood obesity on twitter. Am J Public Health. 2014;104:e62-9.

60. Quirke L. "Fat-proof your child": Parenting advice and "child obesity." Fat studies. 2016;5:137-55.

61. Nimegeer A, Patterson C, Hilton S. Media framing of childhood obesity: a content analysis of UK newspapers from 1996 to 2014. BMJ open. 2019;9:e025646.

62. Goldthorpe J, Ali N, Calam R. Providing healthy diets for young children: the experience of parents in a UK inner city. Int J Qual Stud Health Well Being. 2018;13:1.

63. Kyrölä K. The Weight of Images. 0 edition. Routledge; 2016.

64. Hynnä-Granberg K. "Why can't I take a full-shot of myself? Of course I can!" Studying selfies as sociotechnological affective practices. Fem Media Stud. ahead-of-print:1-16.

65. Hynnä K. Lupanäkyä - kehopositiiviset selfiet affektiivisena käytäntönä. Lähikuva audiovisuaalisen kulttuurin tieteellinen julkaisu. 2018;31:65-72.

66. Tiina Johanna Valkendorff. Lihavuus "itse aiheutettuna ongelmana": Argumentteja internetin keskustelupalstalta. Sosiaalilääketieteellinen aikakauslehti. 2014;51:4-17.

67. Do LM, Larsson V, Tran TK, Nguyen HT, Eriksson B, Ascher H. Vietnamese mother's conceptions of childhood overweight: findings from a qualitative study. Global Health Action. 2016;9:30215.

68. Wu Y, Ma X, Fraser WD, Li M, Wang W, Huang H, et al. Caregivers' perceptions, challenges and service needs related to tackling childhood overweight and obesity: a qualitative study in three districts of Shanghai, China. BMC Public Health. 2021;21:768.

69. Fuller AB, Byrne RA, Golley RK, Trost SG. Supporting healthy lifestyle behaviours in families attending community playgroups: parents' perceptions of facilitators and barriers. BMC Public Health. 2019;19:1-11.

70. Farrell E, Hollmann E, le Roux C W, Bustillo M, Nadglowski J, McGillicuddy D. The lived experience of patients with obesity: A systematic review and qualitative synthesis. Obesity reviews. 2021;22(12):e13334-n/a. 
71. Eli K, Howell K, Fisher PA, Nowicka P. "Those comments last forever": Parents and grandparents of preschoolers recount how they became aware of their own body weights as children. PLoS One. 2014;9:e111974.

72. Ek A, Sorjonen K, Nyman J, Marcus C, Nowicka P. Child behaviors associated with childhood obesity and parents' self-efficacy to handle them: Confirmatory factor analysis of the Lifestyle Behavior Checklist. Int J Behav Nutr Phy. 2015;12:36.

73. Anderson SE, Keim SA. Parent-Child Interaction, Self-Regulation, and Obesity Prevention in Early Childhood. Curr Obes Rep. 2016;5:192-200.

\section{Figures}

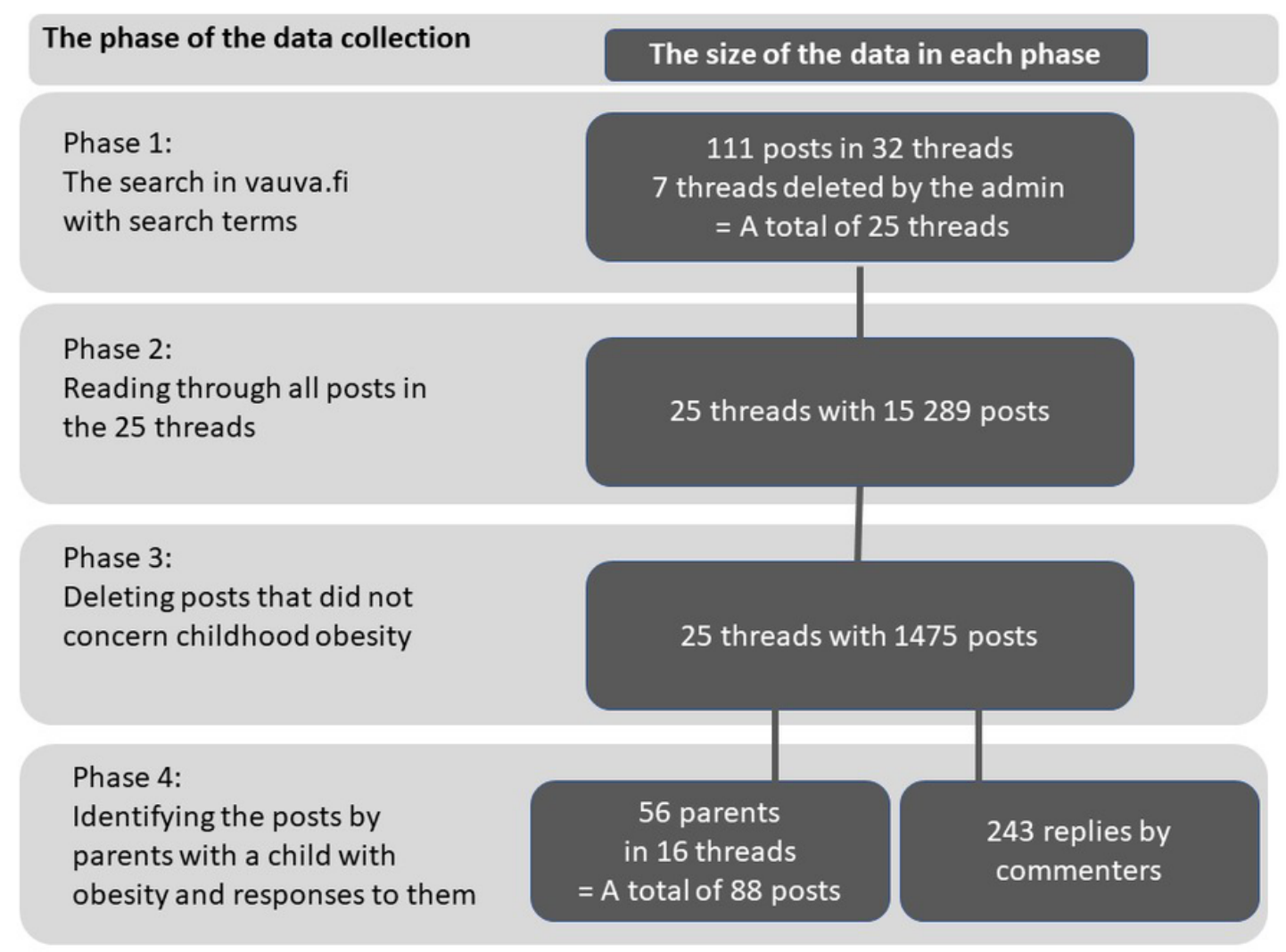

\section{Figure 1}

Steps in data collection. 


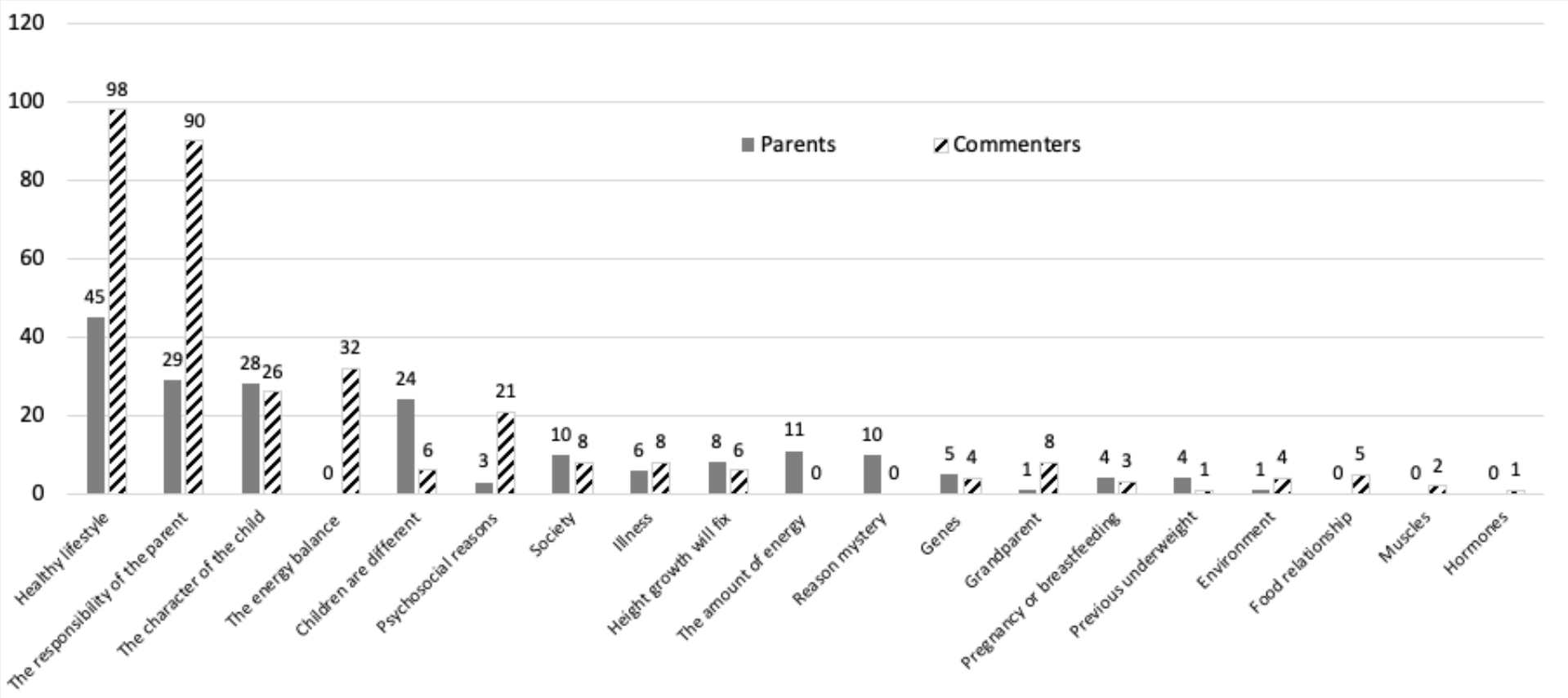

Figure 2

The initial codes and the number of their occurrence in the parents' and commenters' posts.

\section{Supplementary Files}

This is a list of supplementary files associated with this preprint. Click to download.

- Attachment1.docx 